\section{European Medical Research Group (Meeting held on 23 June 1992)}

The European Medical Research Group met at the Medical Society of London, Lettsom House, on 23 June 1992. The guest speaker was Professor R.C.D.S. Coombes who gave a lecture on 'Molecular approach to the future treatment of breast cancer'.

A poster session was held demonstrating the research in progress of some members of the Group, one of which is published below.

\section{Intravenous administration of drugs by preregistration house staff and City and Hackney Health Authority}

Mark Caulfield, Atholl Johnson and Paul Turner

\section{Department of Clinical Pharmacology, St \\ Bartholomew's Hospital Medical College, West Smithfield, London EC1A $7 B E, U K$.}

Over the past 10 years a $150 \%$ increase in the use of intravenous (i.v.) cannulation has occurred. To reduce junior doctors hours to 72 hours by 1994 has necessitated examination of duties such as i.v. administration.,2 Within City and Hackney Health Authority, nurses who have completed an i.v. administration training course may administer second doses of intravenous drugs. The aim of this survey was to define how much i.v. administration was undertaken by house officers and whether there were delays in administration which might affect quality of care.

Forty-seven house staff at St Bartholomew's Hospital were requested to record all i.v. drugs they gave over a 7 day period. They also recorded the ward/speciality and the reason they were asked to undertake the task. Quality of i.v. administration was assessed by recording the time the prescribed drug was due, the time that the nurses asked the doctor to administer the drug, and the time the

\section{References}

1. Zalin, A.M. Cannulas and junior doctors. Br Med J 1989, 299: 1279.

2. Cunningham, S. et al. Workload of pre-registration house officers. $\mathrm{Br}$ Med J 1990, 300: 1342.

3. Bakker-Woudenberg, I.A.J.M. et al. Impact of dosage regimens on the efficacy of antibiotics in the immunocompromised host. J Antimicrob Chemother 1988, 21: 145-150. doctor was actually able to respond to the request to administer the drug.

Fourteen house officers (32\% response rate) gave a total of 208 separate i.v. drugs over 7 days. One hundred and sixty-eight were 'second-dose' drugs available to i.v. certificated nurses and $\mathbf{4 0}$ drugs were drugs only doctors can give. The overwhelming majority of the administration was undertaken by surgical house officers who gave 154 second-dose drugs and 31 first-dose drugs. These were mainly prophylactic antibiotics.

Only $28 \%$ of the i.v. drugs administered by house officers were actually given at the prescribed time. By 1 hour post prescription time this had risen to $62 \%$ and at 2 hours $94 \%$. An important component of this was delay in nurses requesting the doctors to give the drugs with only $58 \%$ of drugs requested to be given at the time they were prescribed (by 1 hour post prescription time $82 \%$ of drugs had been requested). Also, doctors were not able to respond immediately to the request. Only $20 \%$ of the drugs were given immediately upon request and $90 \%$ were given within 1 hour of request.

This study reviews only a fraction of the total intravenous administration burden which falls mainly upon nurses. However, in spite of the response rate of $32 \%$, it is clear that house staff, particularly in surgery, have a large i.v. administration burden. There are substantial time delays in administration which reflect the varied duties of a junior house officer on different wards and also the varied responsibilities of the nursing role. There is no doubt that such time delays in administration of drugs could affect quality of care. For example, ampicillin given 10 hours late could lead to ineffective therapeutic effect. ${ }^{3}$ Nurses and medical staff are working together to reorganize practice to reduce the total intravenous drug burden by modifying prophylactic regimes and considering predrawn drugs prepared by the pharmacy sterile unit. ${ }^{4}$ Intravenous training for nurses is to be moved into the student nurses' curriculum and in the near future trained nurses will administer all i.v. therapy including first doses.
4. Chan, R. \& Feely, J. Delay in administration of intravenous antibiotics and the effect of a centralised reconstitution of intravenous antibiotics service. Br J Clin Pharmacol 1992, 34: 458P. 